\title{
Multi-Objective based Optimal Energy and Reactive Power Dispatch in Deregulated Electricity Markets
}

\author{
Surender Reddy Salkuti \\ Department of Railroad and Electrical Engineering, Woosong University, Daejeon, Republic of Korea
}

\begin{tabular}{l}
\hline \hline Article Info \\
\hline Article history: \\
Received Apr 9, 2018 \\
Revised Jun 8, 2018 \\
Accepted Jun 21, 2018 \\
\hline
\end{tabular}

\section{Keyword:}

Evolutionary algorithms

Load modeling

Market clearing

Multi-objective optimization

Social welfare

\begin{abstract}
This paper presents a day-ahead (DA) multi-objective based joint energy and reactive power dispatch in the deregulated electricity markets. The traditional social welfare in the centralized electricity markets comprises of customers benefit function and the cost function of active power generation. In this paper, the traditional social welfare is modified to incorporate the cost of both active and reactive power generation. Here, the voltage dependent load modeling is used. This paper brings out the unsuitability of traditional single objective functions, e.g., social welfare maximization (SWM), loss minimization (LM) due to the reduction of amount of load served. Therefore, a multi-objective based optimization is required. This paper proposes four objectives, i.e., SWM, load served maximization (LSM), LM and voltage stability enhancement index (VSEI); and these objectives can be combined as per the operating condition. The simulation studies are performed on IEEE 30 bus test system by considering the both traditional constant load modeling and the proposed voltage dependent load modeling.
\end{abstract}

Copyright $@ 2018$ Institute of Advanced Engineering and Science. All rights reserved.

\section{Corresponding Author:}

Surender Reddy Salkuti,

Department of Railroad and Electrical Engineering,

Woosong University,

Jayang-dong, Dong Gu, Daejeon, 300718, Republic of Korea.

Email: surender@wsu.ac.kr

\section{NOMENCLATURE}

$\mathrm{a}_{0} \quad$ Availability price offer (in \$).

$\mathrm{N}_{\mathrm{G}} \quad$ Number of generators participating in the market clearing.

$\mathrm{N}_{\mathrm{D}} \quad$ Number of load demands participating in the market clearing.

np, nq Voltage exponents.

$P_{G i}^{k} \quad$ Active power output from $\mathrm{i}^{\text {th }}$ generating unit at hour $\mathrm{k}$.

$R R_{i} \quad$ Ramp rate limits of $\mathrm{i}^{\text {th }}$ generating unit.

$\mathrm{C}_{\mathrm{Gi}}\left(\mathrm{P}_{\mathrm{Gi}}\right) \quad$ Cost function for generating the active power $\mathrm{P}_{\mathrm{Gi}}$.

$\mathrm{B}_{\mathrm{Di}}\left(\mathrm{P}_{\mathrm{Di}}\right) \quad$ Demand function at bus $\mathrm{i}$.

$a_{i}, b_{i}, c_{i} \quad$ Generator cost coefficients of $i^{\text {th }}$ generator bus.

$d_{i}, e_{i}, f_{i} \quad$ Demand function coefficients of $i^{\text {th }}$ load bus.

$\mathrm{Q}_{1, \mathrm{i}} \quad$ Operating region between $\left(\mathrm{Q}_{\min }<\mathrm{Q} \leq 0\right)$.

$\mathrm{Q}_{2, \mathrm{i}} \quad$ Operating region between $\left(\mathrm{Q}_{\text {base }}<\mathrm{Q} \leq \mathrm{Q}_{\mathrm{A}}\right)$.

$\mathrm{Q}_{3, \mathrm{i}} \quad$ Operating region between $\left(\mathrm{Q}_{\mathrm{A}}<\mathrm{Q} \leq \mathrm{Q}_{\mathrm{B}}\right)$.

$\rho_{e}^{i} \quad$ Bid price of $i^{\text {th }}$ generator.

$\rho_{e}^{M C P} \quad$ Market Clearing Price (MCP) of energy only market.

\section{INTRODUCTION}

Independent System Operator (ISO) collects the half-hourly/hourly supply bids from the generation companies (GENCOs) and demand bids from distribution companies (DISCOs) for solving the day-ahead 
(DA) market clearing (generation and load demand schedule) problem. In the deregulated power industry, establishing an effective and equitable reactive power market with the consideration of the voltage security problem is very important to provide a reliable power system. Ancillary services are necessary to support the transmission of electric power from producers to customers. These services are needed to ensure that the ISOs are able to meet their responsibilities and to enhance the system maintenance, reliability and quality.

Reference [1] proposes a new structure for joint energy and reactive power market to resolve the difficulties pertaining interactions between the active and reactive power markets. A stochastic multiobjective optimization (MOO) algorithm for simultaneous active and reactive power dispatch in electricity markets with wind power volatility is proposed in [2]. Reference [3] proposes a dispatching reactive power model based on optimal power flow (OPF) by which both the cost of procuring reactive power as auxiliary service and the losses of active power are minimized. Reference [4] deals with the obtaining, decomposition and deduction of behavior rules of spot prices, and their influence on established contractual relationships in a deregulated market environment which allows the power purchase agreements between consumers and producers. A new reactive power market structure is presented in [5] to improve the reactive power market and create fair competition between producers. An efficient stochastic framework to develop a coupled active and reactive market in smart distribution systems is proposed in [6]. Reference [7] presents an algorithm for procuring reactive power from reactive resources based on a reactive power pricing structure. Reference [8] proposes two new active/reactive dispatch models to be used by System Operators in order to assign reactive power and to validate the economic schedules prepared by Market Operators together with the injections related with bilateral contracts. A deterministic model of complete generation-grid system to obtain the active and reactive power spot prices and their decomposition, to deduce general rules concerning their behaviour, and to analyze the effect of the applied constraints is proposed in [9]. A new probabilistic algorithm for optimal reactive power provision in hybrid electricity markets is proposed in Reference [10].

The real and reactive power dispatch models used by the ISOs to assign the reactive power and to validate the economic schedules prepared by the market operators with bilateral contracts is described in Reference [11]. A multi-objective based day-ahead reactive power market clearing model is proposed in Reference [12]. A joined real and reactive power market clearing in the restructured electrical systems is presented in Reference [13]. In [14], uses multi-objective directed bee colony optimization algorithm to optimize the combined emission and generation cost. An optimal reactive power scheduling problem in restructured power system using the evolutionary based Cuckoo Search Algorithm is proposed in [15]. A meta-heuristic based approach to solve the Optimal Reactive Power Dispatch problem using Crow Search algorithm is proposed in [16].

From the literature review, it can be observed that most of the works in the literature doesn't considers the energy and reactive markets, simultaneously. Therefore, the motivation of this paper is to clear the market by optimizing both the energy and reactive powers, simultaneously, and considering the voltage dependent load modeling. In this paper, it is considered that the traditional single objectives such as Social Welfare Maximization (SWM) and Loss Minimization (LM) objectives are not feasible with voltage dependent load modeling due to the reduction in the amount of load served (LS). A MOO is required for solving the problems of this kind.

\section{SEPARATE ACTIVE AND REACTIVE POWER MARKET CLEARING}

Typically, the market clearing problem is solved by the system operator to know the accepted offers and bids and the resulting Market Clearing Price (MCP).

\subsection{Centralized separate energy market}

The concept of social welfare maximization (SWM) can be applied for the centralized electricity market with demand elasticity. The social welfare (SW) is the total surplus of generators and customers. The system operator solves the SWM [17] objective function, and it is formulated as,

$$
S W M=\operatorname{maximize}\left[\sum_{i=1}^{N_{D}} B_{D i}\left(P_{D i}\right)-\sum_{i=1}^{N_{G}} C_{G i}\left(P_{G i}\right)\right]
$$

Where

$$
\begin{aligned}
& C_{G i}\left(P_{G i}\right)=a_{i}+b_{i} P_{G i}+c_{i} P_{G i}^{2} \\
& B_{D i}\left(P_{D i}\right)=d_{i}-e_{i} P_{D i}-f_{i} P_{D i}^{2}
\end{aligned}
$$




\subsection{Reactive power market clearing}

The synchronous generator's capability curve [18] consists of 3 operating regions. These regions reflect the armature, field current heatings and the under-excitation limits.

\subsubsection{Reactive power bid structure}

Similar to the real power, synchronous generators bids for the reactive power [18]. These bids consist of a capacity component which is paid in advance for their readiness to absorb/ produce the reactive power.

Expected Payment Function (EPF): The reactive power payment of generators consists of different cost components depending upon their operating regions. EPF is a mathematical formulation of generator reactive power cost components of generator's expectation of payment towards utilization, capacity and compensation components. Figure 1 depicts the EPF of a generating unit, as a function of amount of reactive power output. The terms of EPF i.e., opportunity cost, cost of loss are presented in Reference [18].

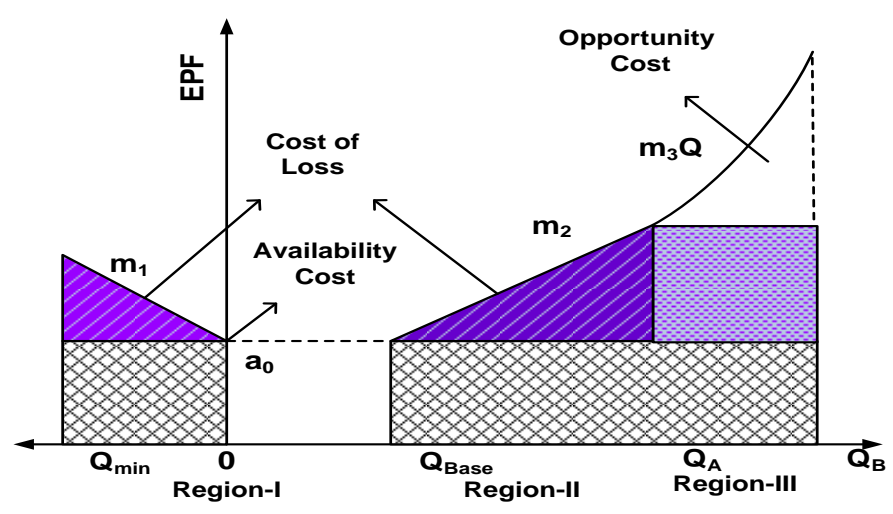

Figure 1. Structure of reactive power offers from the generating units

Figure 1 depicts the operating regions of generator on the reactive power coordinates and these regions are clearly presented in Reference [19]. The expected payment function (EPF) of a generator is expressed as,

$$
E P F_{i}=a_{0, i}+\int_{Q_{\min }}^{0} m_{1, i} d Q_{i}+\int_{Q_{\text {base }}}^{Q_{A}} m_{2, i} d Q_{i}+\int_{Q_{A}}^{Q_{B}} m_{3, i} d Q_{i}
$$

Where $\mathrm{a}_{0}, \mathrm{~m}_{1}, \mathrm{~m}_{2}$ and $\mathrm{m}_{3}$ in the above equation represent different components of reactive power cost offered by the generator. $\mathrm{m}_{1}$ is cost of loss price offer for operation in the under-excited mode $\left(\mathrm{Q}_{\min } \leq \mathrm{Q} \leq 0\right)(\$ /$ Mvar-h$), \mathrm{m}_{2}$ is cost of loss price offer for the operating in region $\left(\mathrm{Q}_{\text {base }} \leq \mathrm{Q} \leq \mathrm{Q}_{\mathrm{A}}\right)$ in $(\$ / M v a r-h)$, and $m_{3}$ is opportunity price offer, for operating in region $\left(\mathrm{Q}_{\mathrm{A}} \leq \mathrm{Q} \leq \mathrm{Q}_{\mathrm{B}}\right)((\$ M V \operatorname{ar}-\mathrm{h}) / \mathrm{MVar}-\mathrm{h})$. The Total Payment Function (TPF) is expressed as [20], The last term in equation 5 represents the LOC payment.

$$
T P F=\sum_{i=1}^{N_{G}}\left[\begin{array}{c}
\rho_{0} W_{0, I}-\rho_{1} W_{1, i} Q_{1, i}+\rho_{2} W_{2, i}\left(Q_{2, i}-Q_{\text {base }, i}\right)+\rho_{2} W_{3, i}\left(Q_{3, i}-Q_{\text {base }, i}\right) \\
+\frac{1}{2}\left(\rho_{3} W_{3}\left(Q_{3, i}^{2}-Q_{\text {base }, i}^{2}\right)\right)
\end{array}\right]
$$

\section{DESIGN OF COUPLED ACTIVE AND REACTIVE POWER MARKET CLEARING}

In this section, different objective functions for the coupled ARPMC are proposed.

\subsection{Loss opportunity cost (LOC) formulation}

The LOC of a generator plays a vital role in the reactive power scheduling and pricing [19]. To use the LOC in Equation (7), the results of separate energy dispatch are required. Therefore, the separate energy dispatch must be performed before the coupled ARPMC problem. Here, the LOC of a generator, which is 
forced to produce the reactive power, can be expressed as [20]:

$$
\begin{aligned}
L O P_{G}^{i} & =\left\{\begin{array}{lr}
\rho_{e}^{M C P}-\rho_{e}^{i} & \text { if } \rho_{e}^{M C P}>\rho_{e}^{i} \\
0 & \text { if } \rho_{e}^{M C P} \leq \rho_{e}^{i}
\end{array}\right. \\
\operatorname{LOC}_{G}^{i} & =\max \left[0, L O P_{G}^{i}\left(P_{G 0}^{i}-P_{G}^{i}\right)\right]
\end{aligned}
$$

The TPF for reactive power compensation in coupled ARPMC consists only operation and availability payments [18], and this can be expressed as,

$$
T P F=\sum_{i=1}^{N_{G}}\left[\rho_{0} W_{0, I}-\rho_{1} W_{1, i} Q_{1, i}+\rho_{2} W_{2, i}\left(Q_{2, i}-Q_{\text {base }, i}\right)\right]
$$

\subsection{Load modeling}

Generally, the active and reactive power loads are modeled as the constant power loads. But, they are voltage dependent [21] in the practical real time operation. In this paper, for the sake of simplicity, exponential load demand model is used, and it can be expressed as,

$$
\begin{aligned}
& P_{L i}=P_{L i}^{0}\left(\frac{V_{i}}{V_{i}^{0}}\right)^{n p} \\
& Q_{L i}=Q_{L i}^{0}\left(\frac{V_{i}}{V_{i}^{0}}\right)^{n q}
\end{aligned}
$$

where $n p$ and $n q$ are depend on composition and type of the load demand. The objective functions considered in the centralized DA coupled ARPMC problem are as follows.

\subsection{Social welfare maximization (SWM) in coupled ARPMC}

In this paper, an OPF based approach is used to find the market clearing price (MCP), and to get the active and reactive power schedules that satisfy the system operation requirements. In coupled ARPMC model, the objective is to maximize social welfare (SW). SWM objective function can be formulated as [17], SWM is an important objective under all system operating conditions.

$$
\text { maximize, } S W=\sum_{i=1}^{N_{D}} B_{D i}\left(P_{D i}\right)-\sum_{i=1}^{N_{G}} C_{G i}\left(P_{G i}\right)+T P F+\sum_{i=1}^{N_{G}} L O C_{i}\left(Q_{G i}\right)
$$

\subsection{Loss minimization (LM)}

The goal of this objective is to find the optimal settings of control variables which result in optimum transmission losses. The LM objective is suitable only for the constant load modeling at light loading condition. If load demands are modeled as voltage dependent, the SWM and LM objectives lead to the load served (LS) reduction through the voltage reduction. This LM objective is expressed as [22],

$$
L M=0.5 \sum_{i, j}\left[G_{i j}\left(V_{i}^{2}+V_{j}^{2}-2 V_{i} V_{j} \cos \left(\delta_{i}-\delta_{j}\right)\right)\right]
$$

\subsection{Amount of load served maximization (LSM)}

The practice, the load demands are the function of voltages, therefore the voltage dependent load modeling is utilized. The improvement of system voltages increases the amount of load served (LS). Under the voltage dependent load modeling, the LSM objective is appropriate at light loading conditions, and it is formulated as Equation (13). This LSM objective will never be used as an independent objective.

$$
L S M=\sum_{i=1}^{n} P_{L i}^{0}\left(\frac{V_{i}}{V_{i}^{0}}\right)^{n p}
$$

\subsection{Voltage stability enhancement index (VSEI)}

To monitor the voltage stability in the system, L-index [23] of the load/demand buses is considered. L-index/VSEI uses the information from the power flow and is in the range of 0 (no load) to 1 (voltage collapse). L-index presents the stability of complete system, and it is expressed as, 


$$
\begin{gathered}
L_{j}=\left|1-\sum_{i=1}^{n g} F_{j i} \frac{E_{i}}{E_{j}}\right| \\
L-\text { index }=\text { VSEI }=\sum_{j=n g+1}^{n} L_{j}^{2}
\end{gathered}
$$

where $\mathrm{j}=\mathrm{ng}+1, \ldots, \mathrm{n}$. The values of $\mathrm{F}_{\mathrm{ji}}$ are calculated from the Y-Bus matrix [18]. In the case of voltage dependent load modeling, the L-index/VSEI minimization objective improves the voltage profile of the system and hence the amount of load served (LS).

\subsection{Equality and inequality constraints for the coupled ARPMC problem}

\subsubsection{Equality constraints}

The nodal power balance constraints include the active and reactive power balance equations. They are expressed as,

$$
\begin{aligned}
& P_{G i}-P_{D i}=\sum_{j}\left[V_{i} V_{j} Y_{i j} \cos \left(\theta_{i j}+\delta_{j}-\delta_{i}\right)\right] \\
& Q_{G i}-Q_{D i}=\sum_{j}\left[V_{i} V_{j} Y_{i j} \sin \left(\theta_{i j}+\delta_{j}-\delta_{i}\right)\right]
\end{aligned}
$$

\subsubsection{Generator constraints}

The generator outputs are limited by their minimum and maximum active power outputs as,

$$
\max \left[P_{i}^{\min }, P_{G i}^{k-1}-R R_{i}^{\text {down }}\right] \leq P_{G i}^{k} \leq \min \left[P_{i}^{\max }, P_{G i}^{k-1}+R R_{i}^{u p}\right]
$$

Using the reactive power offers from the generators in different operating regions, the constraints are formulated as,

$$
\begin{aligned}
& Q_{i}=Q_{1, i}+Q_{2, i} \\
& W_{1, i} Q_{\text {min }, i} \leq Q_{1, i} \leq W_{1, i} Q_{\text {base }, i} \\
& W_{2, i} Q_{\text {base }, i} \leq Q_{2, i} \leq W_{2, i} Q_{\max , i} \\
& W_{1, i}+W_{2, i} \leq W_{0, i}
\end{aligned}
$$

\subsubsection{Demand limits}

$$
\begin{aligned}
& P_{D i}^{\min } \leq P_{D i} \leq P_{D i}^{\max } \\
& Q_{D i}^{\min } \leq Q_{D i} \leq Q_{D i}^{\max }
\end{aligned}
$$

\subsubsection{Constraints on MCPs}

$$
\begin{aligned}
& W_{0, i} a_{0, i} \leq \rho_{0} \\
& W_{1, i} m_{1, i} \leq \rho_{1} \\
& W_{2, i} m_{2, i} \leq \rho_{2}
\end{aligned}
$$

\subsubsection{Generator reactive power constraints}

$$
\begin{aligned}
& Q_{i}^{G} \leq \sqrt{\left(\frac{V_{t}^{i} E_{a f}^{i}}{X_{s}^{i}}\right)^{2}-P_{G i}^{2}}-\frac{\left(V_{t}^{i}\right)^{2}}{X_{s}^{i}} \\
& Q_{i}^{G} \leq \sqrt{\left(V_{t}^{i} I_{a}^{i}\right)^{2}-P_{G i}^{2}}
\end{aligned}
$$


The minimum limit of reactive power generation $\left(\mathrm{Q}_{\mathrm{i}}^{\min }\right)$ is given by,

$$
Q_{i}^{\text {min }} \leq Q_{i}^{G}
$$

\subsubsection{Security constraints}

$$
\begin{aligned}
& V_{i}^{\text {min }} \leq V_{i} \leq V_{i}^{\text {max }} \\
& \left|S_{p q}\right| \leq S_{p q}^{\text {max }} \\
& T_{i}^{\text {min }} \leq T_{i} \leq T_{i}^{\text {max }}
\end{aligned}
$$

where $S_{p q}$ is power flow in a line/MVA flow, $S_{p q}^{\max }$ is maximum power flow/thermal limit of the transmission line connected between the buses $\mathrm{p}$ and $\mathrm{q}$. In this paper, the single objective optimization problem is solved using the Genetic Algorithm (GA), and the Strength Pareto Evolutionary Algorithm 2+ (SPEA 2+) algorithm is used to solve the coupled ARPMC problem. The fuzzy min-max approach [22] is used to determine the best-compromise solution [24].

\section{SIMULATION RESULTS AND DISCUSSION}

Here, IEEE 30 bus system [25] is considered to test the effectiveness and feasibility of the proposed centralized day-ahead (DA) coupled ARPMC problem. Five generator active powers, 21 power demands, 6 generator bus voltage magnitudes, 4 transformer taps and 9 bus shunt admittances are considered as the control variables. Here, the exponential (i.e., voltage dependent) load modeling with $\mathrm{np}=1$ and $\mathrm{nq}=2$ are utilized [18]. In this paper, they assumed as $\mathrm{Q}_{\mathrm{Base}}=0.1 * \mathrm{Q}_{\max } ; \mathrm{Q}_{\mathrm{A}}$ is restricted by armature or field heating limit; $\mathrm{Q}_{\mathrm{B}}=1.5 * \mathrm{Q}_{\mathrm{A}}$.

\subsection{Case study 1: Solving the coupled ARPMC problem using the constant load modeling with light loading condition}

Table 1 presents the control variables and objective function values for the Case Study 1 considering the single and multiple objectives with constant load modeling. When the SWM objective is optimized independently then the obtained SW is $602.88 \$ / \mathrm{hr}$, which is the optimum value, but VSEI and losses are deviated from the optimum. When LM objective is optimized independently, then the obtained optimum loss is $2.8977 \mathrm{MW}$, but the obtained SW and VSEI are not optimum. In the same way, when one objective function is optimized independently, then the other objectives are deviated from the optimum value. Therefore, there exists a conflict between the optimum objective values when one objective is optimized independently.

Table 1. Optimum Objective Function Values and Control Variables for Case Study 1

\begin{tabular}{ccccc}
\hline Objective \& Control & \multicolumn{3}{c}{ Single Objective ARPPC } & MO ARPPC \\
variables values & SWM & LM & VSEI & SWM \& LM \\
\hline $\mathrm{P}_{\mathrm{G} 1}(\mathrm{MW})$ & 162.49 & 62.87 & 106.53 & 77.23 \\
$\mathrm{P}_{\mathrm{G} 2}(\mathrm{MW})$ & 49.67 & 72.10 & 67.99 & 64.44 \\
$\mathrm{P}_{\mathrm{G} 5}(\mathrm{MW})$ & 24.35 & 44.78 & 28.08 & 41.25 \\
$\mathrm{P}_{\mathrm{G} 8}(\mathrm{MW})$ & 26.78 & 33.42 & 34.60 & 34.96 \\
$\mathrm{P}_{\mathrm{G} 11}(\mathrm{MW})$ & 12.81 & 25.69 & 10.40 & 29.99 \\
$\mathrm{P}_{\mathrm{G} 13}(\mathrm{MW})$ & 12.89 & 29.48 & 26.04 & 25.73 \\
$\mathrm{~V}_{1}(\mathrm{pu})$ & 1.0206 & 1.0488 & 1.0947 & 1.0934 \\
$\mathrm{~V}_{2}(\mathrm{pu})$ & 1.0565 & 1.0424 & 1.1000 & 1.0959 \\
$\mathrm{~V}_{5}(\mathrm{pu})$ & 1.0088 & 1.0294 & 1.0994 & 1.0759 \\
$\mathrm{~V}_{8}(\mathrm{pu})$ & 1.0424 & 1.0247 & 1.0994 & 1.0847 \\
$\mathrm{~V}_{11}(\mathrm{pu})$ & 1.0959 & 1.0953 & 1.0994 & 1.0888 \\
$\mathrm{~V}_{13}(\mathrm{pu})$ & 1.0347 & 1.0965 & 1.0994 & 1.0988 \\
Generation (in MW) & 288.99 & 268.34 & 273.64 & 273.60 \\
Amount of Load Served (in MW) & 278.38 & 265.45 & 267.58 & 269.85 \\
Generation Cost (in \$/hr) & 1336.75 & 1452.42 & 1346.83 & 1415.14 \\
Demand Cost (in \$/hr) & 1939.63 & 1868.65 & 1891.58 & 1905.85 \\
Social Welfare (in \$/hr) & 602.88 & 416.24 & 544.75 & 490.71 \\
Total System Losses (in MW) & 10.6041 & 2.8977 & 6.0629 & 3.7451 \\
VSEI & 0.12296 & 0.10702 & 0.06133 & 0.08647 \\
\hline
\end{tabular}


In this case study, SWM and LM objectives are selected as the appropriate objectives for the DA multi-objective coupled ARPMC problem. As it is the normal operating condition, the VSEI value is away from the voltage collapse point, so there is no need to optimize the VESI objective. Figure 2 depicts the Pareto optimal set of SWM and LM objectives for multi-objective based coupled ARPMC problem for case study 1. In this paper, SPEA 2+ algorithm is used to obtain the Pareto optimal front. The best-compromise solution can be obtained by using the fuzzy min-max method. The obtained best-compromise solution has the social welfare of $490.71 \mathrm{\$} / \mathrm{hr}$, and the loss of $3.7451 \mathrm{MW}$, and this is the better compromise solution as compared to the single objective coupled ARPMC problem.

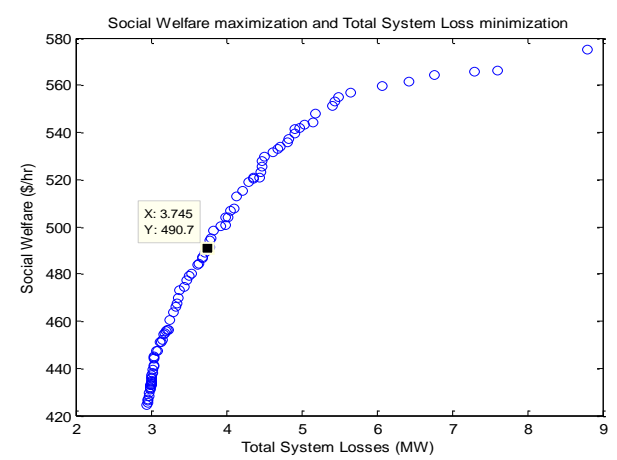

Figure 2. Pareto optimal front of SWM and LM objectives for case study 1

\subsection{Case Study 2: Coupled ARPMC with voltage dependent load modeling at light loading condition}

Table 2 depicts the control variables and objective function values obtained when the single and multiple objectives are optimized with voltage dependent load modeling. When the social welfare maximization objective is optimized individually, then the obtained optimum SW is $580.64 \$ / \mathrm{hr}$, and it is less than the social welfare obtained by constant load modeling, and load served (LS) is $259.46 \mathrm{MW}$, which is less than the load served by the constant load modeling. In this case, the SWM leads to reduction in voltages and therefore, the reduction in the amount of load served (LS). Due to this reason, the SWM should not be optimized individually. When the LSM objective is optimized individually, then the amount of load served (LS) is $314.90 \mathrm{MW}$, but the social welfare has decreased to $537.97 \$ / \mathrm{hr}$. As explained earlier, the LSM objective cannot be used as an independent objective.

Table 2. Optimum Objective Function Values and Control Variables for Case Study 2

\begin{tabular}{ccccc}
\hline & \multicolumn{3}{c}{ Single Objective ARPMC } & MO ARPMC \\
Objective \& Control Variables Values & SWM & LSM & VSEI & SWM \& LSM \\
\hline $\mathrm{P}_{\mathrm{G} 1}(\mathrm{MW})$ & 144.89 & 120.08 & 158.36 & 132.50 \\
$\mathrm{P}_{\mathrm{G} 2}(\mathrm{MW})$ & 49.13 & 66.40 & 44.06 & 65.57 \\
$\mathrm{P}_{\mathrm{G} 5}(\mathrm{MW})$ & 23.94 & 47.50 & 45.15 & 36.95 \\
$\mathrm{P}_{\mathrm{G} 8}(\mathrm{MW})$ & 24.55 & 34.53 & 25.48 & 34.71 \\
$\mathrm{P}_{\mathrm{G} 11}(\mathrm{MW})$ & 15.07 & 28.07 & 10.06 & 10.32 \\
$\mathrm{P}_{\mathrm{G} 13}(\mathrm{MW})$ & 12.3 & 25.55 & 12.57 & 17.65 \\
$\mathrm{~V}_{1}(\mathrm{pu})$ & 0.9529 & 1.0718 & 1.0971 & 1.0768 \\
$\mathrm{~V}_{2}(\mathrm{pu})$ & 0.9959 & 1.0988 & 1.0912 & 1.0613 \\
$\mathrm{~V}_{5}(\mathrm{pu})$ & 0.95 & 1.1 & 1.0912 & 1.0796 \\
$\mathrm{~V}_{8}(\mathrm{pu})$ & 0.9541 & 1.1 & 1.1 & 1.0671 \\
$\mathrm{~V} 11(\mathrm{pu})$ & 0.95 & 1.0988 & 1.1 & 1.0542 \\
V13 (pu) & 0.9512 & 1.0994 & 1.0941 & 1.0583 \\
Generation (in MW) & 269.87 & 322.13 & 295.68 & 297.70 \\
Total System Losses (in MW) & 10.4092 & 7.231 & 7.6954 & 8.0654 \\
Generation Cost (in \$/hr) & 1278.40 & 1558.88 & 1412.36 & 1405.21 \\
Demand Cost (in \$/hr) & 1859.05 & 2096.85 & 1970.38 & 1967.91 \\
Social Welfare (in \$/hr) & 580.64 & 537.97 & 558.02 & 562.70 \\
Amount of Load Served (in MW) & 259.46 & 314.90 & 287.98 & 289.63 \\
VSEI & 0.29138 & 0.10192 & 0.07499 & 0.15043 \\
\hline
\end{tabular}

When the VSEI objective is optimized individually, then the obtained optimum value is 0.07499 , which is away from the voltage collapse point. Hence, there is no need to optimize VSEI at this operating 
condition. Therefore, the SWM and LSM objectives are considered to be the appropriate multiple objectives to be optimized simultaneously. The compromise solution has social welfare of $562.70 \$ / \mathrm{hr}$ and $289.63 \mathrm{MW}$ of load served. Figure 3 depicts the Pareto optimal front of SWM and LSM objectives for the coupled ARPMC for Case Study 2.

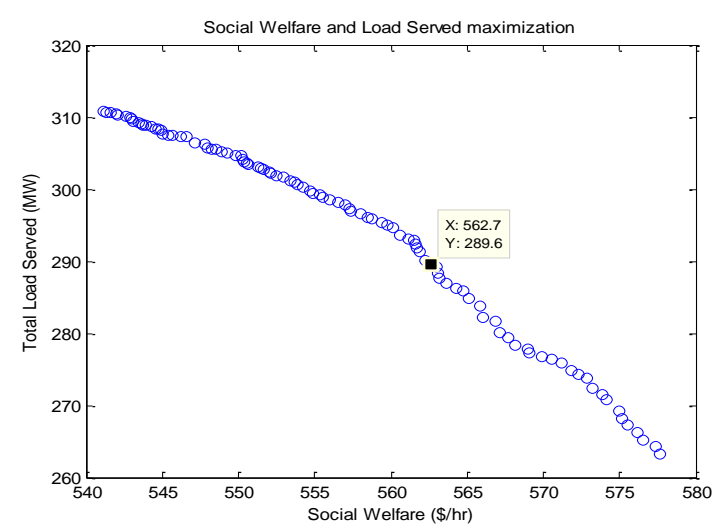

Figure 3. Pareto optimal set of SWM and LSM objectives for case study 2

In this paper, it has been shown that the LM and SWM objectives do not make valid single or joint objectives with this voltage dependent load model, due to reduction of load served. SWM and LSM are best suited objectives to be optimized simultaneously for light to moderate loading condition.

\section{CONCLUSIONS}

This paper has proposed a day-ahead (DA) multi-objective based centralized coupled active and reactive power scheduling and pricing mechanism using the practical voltage dependent load modeling. Different objective functions such as SWM, LSM, LM and VSEI are proposed. The SWM objective includes the offer cost for generators active power production, reactive compensations and the LOC payments for generators and benefit function of customers. In this paper, it is shown that SWM and LM objectives do not make valid single or multiple objectives with the voltage dependent load model, due to the reduction in the amount of load served (LS). Simulation studies on IEEE 30 bus test system shows the suitable and optimum choice of multiple objectives to be selected for a given operating condition. SWM and LSM objectives are appropriate for unstressed loading condition to moderate loading condition, with voltage dependent load modeling. The Pareto optimal front allows the system operator to make a better decision, by considering the better compromised solution.

\section{ACKNOWLEDGMENTS} $2018 "$

This research work is based on the support of "Woosong University Academic Research Funding-

\section{REFERENCES}

[1] H. Ahmadi A.A. Foroud, "Joint Energy and Reactive Power Market Considering Coupled Active and Reactive Reserve Market Ensuring System Security”, Arabian Journal for Science and Engineering, vol. 39, no. 6, pp. 4789-4804, Jun. 2014.

[2] A. Kargarian, B. Falahati and Y. Fu, "Stochastic Active and Reactive Power Dispatch in Electricity Markets with wind Power Volatility", IEEE Power and Energy Society General Meeting, San Diego, CA, 2012, pp. 1-7.

[3] A. Abbasy, I. Tabatabaii and S.H. Hosseini, "Optimal Reactive Power Dispatch in Electricity Markets Using A Multiagent-Based Differential Evolution Algorithm", International Conference on Power Engineering, Energy and Electrical Drives, Setubal, Portugal, pp. 249-254, 2007.

[4] J.I. García-Román, E. González-Romera, "Analysis and Decomposition of Active and Reactive Power Spot Price in Deregulated Electricity Markets”, International Journal of Electrical Power \& Energy Systems, vol. 73, pp. 539547, Dec. 2015. 
[5] A. Ahmadimanesh, M. Kalantar, "A Novel Cost Reducing Reactive Power Market Structure for Modifying Mandatory Generation Regions of Producers”, Energy Policy, vol. 108, pp. 702-711, Sept. 2017.

[6] A. Samimi, M. Nikzad, P. Siano, "Scenario-based Stochastic Framework for Coupled Active and Reactive Power Market in Smart Distribution Systems with Demand Response Programs”, Renewable Energy, vol. 109, pp. 22-40, Aug. 2017.

[7] X.R. Li, C.W. Yu, W.H. Chen, "A Novel Value based Reactive Power Procurement Scheme in Electricity Markets", International Journal of Electrical Power \& Energy Systems, vol. 43, no. 1, pp. 910-914, Dec. 2012.

[8] M.H.R. Gomes, J.T. Saraiva, "Active/Reactive bid based Dispatch Models to be used in Electricity Markets", Electric Power Systems Research, vol. 78, no. 1, pp. 106-121, Jan. 2008.

[9] J.I.García-Román, "Analysis and Decomposition of the Electricity Market Active and Reactive Power Spot Price under Centralized Management", International Journal of Electrical Power \& Energy Systems, vol. 43, no. 1, pp. 1179-1184, Dec. 2012

[10] A. Kargarian, M. Raoofat, M. Mohammadi, "Probabilistic Reactive Power Procurement in Hybrid Electricity Markets with Uncertain Loads", Electric Power Systems Research, vol. 82, no. 1, pp. 68-80, Jan. 2012.

[11] M.H.R. Gomes, J.T. Saraiva, "Active/Reactive bid based Dispatch Models to be used in Electricity Markets", Electric Power Systems Research, vol. 78, pp. 106-121, 2008.

[12] A. Rabiee, H. Shayanfar, N. Amjady, "Multi-objective Clearing of Reactive Power Market in Deregulated Power Systems", Applied Energy, vol. 86, no. 9, pp. 1555-1564, Sept. 2009.

[13] A. Rabiee, H. Shayanfar, N. Amjady, "Coupled Energy and Reactive Power Market Clearing Considering Power System Security”, Energy Conversion and Management, vol. 50, no. 4, pp. 907-915, Apr. 2009.

[14] S.K. Gachhayat, S.K. Dash, P. Ray, "Multi Objective Directed Bee Colony Optimization for Economic Load Dispatch With Enhanced Power Demand and Valve Point Loading", International Journal of Electrical and Computer Engineering, vol. 7, no. 5, pp. 2382-2391, Oct. 2017.

[15] S. Surender Reddy, “Optimal Reactive Power Scheduling Using Cuckoo Search Algorithm”, International Journal of Electrical and Computer Engineering, vol. 7, no. 5, pp. 2349-2356, Oct. 2017.

[16] R. Kumar A, Lakshmi M, "Optimal Reactive Power Dispatch using Crow search Algorithm", International Journal of Electrical and Computer Engineering, vol. 8, no. 3, Jun. 2018.

[17] J. Wu, X. Guan, F. Gao, and G. Sun, "Social Welfare Maximization Auction for Electricity Markets with Elastic Demand", Proc. of the 7th World Congress on Intelligent Control and Automation, June 2008, pp. 7157-7162.

[18] S.S. Reddy, A.R. Abhyankar, P.R. Bijwe, "Reactive Power Price clearing using Multi-objective Optimization", Energy, vol. 36, pp. 3579-3589, 2011.

[19] S.S. Reddy, A.R. Abhyankar, P.R. Bijwe, "Optimal day-ahead joint Energy and Reactive Power Scheduling with voltage dependent load models", IEEE Transportation Electrification Conference and Expo, Asia-Pacific (ITEC Asia-Pacific), Busan, 2016, pp. 198-202.

[20] S.S. Reddy, A.R. Abhyankar, P.R. Bijwe, "Market Clearing of Joint Energy and Reactive Power using Multi Objective Optimization considering Voltage Dependent Load Models", IEEE Power and Energy Society General Meeting, 24-29 July 2011, pp.1-8.

[21] S.S. Reddy, A.R. Abhyankar, P.R. Bijwe, "Multi-Objective Day-Ahead Real Power Market Clearing with Voltage Dependent Load Models", International Journal of Emerging Electric Power Systems, vol. 12, no. 4, pp. 1-22, Aug. 2011.

[22] S.S. Reddy, P.R. Bijwe, "Multi-Objective Optimal Power Flow Using Efficient Evolutionary Algorithm", International Journal of Emerging Electric Power Systems, vol. 18, no. 2, Apr. 2017.

[23] Bansilal, D. Thukaram, Parthasarathy, "Optimal Reactive Power Dispatch Algorithm for Voltage Stability Improvement”, Electrical Power and Energy Systems, vol. 18, pp. 461-468, 1996.

[24] M. Kim, T. Hiroyasu, M. Miki, "SPEA 2+: Improving the Performance of the Strength Pareto Evolutionary Algorithm 2", Parallel Problem Solving from Nature-PPSN VIII, pp. 742-751, 2004.

[25] [Online]. Available: http://www.ee.washington.edu/research/pstca. 